\title{
RECONFIGURAÇÃO DAS RELAÇÕES DE GÊNERO E COTIDIANO DAS MULHERES EDUCANDAS DA EJA
}

\author{
BASTOS, Ludimila Corrêa ${ }^{1 *}$; EITERER, Carmem Lucia ${ }^{1 * *}$ \\ ${ }^{1}$ Universidade Federal de Minas Gerais \\ ludimilacorrea@yahoo.com.br ${ }^{*}$ \\ eiterer@oi.com.br**
}

\section{RESUMO}

Este artigo é fruto de pesquisa de natureza qualitativa realizada a partir de depoimentos coletados por meio de entrevistas semiestruturadas. Discute-se aqui um aspecto relativo às negociações que mulheres trabalhadoras e mães de filhos pequenos estabelecem em suas residências a fim de garantir a possibilidade de frequentar a escola noturna. Nesse sentido, a pesquisa inscreve-se no âmbito dos trabalhos que discutem como as relações de gênero se estabelecem no cotidiano.

PALAVRAS-CHAVE: Educação de adultos. Gênero. Conciliação escola-trabalho.

\section{RECONFIGURATION OF GENDER RELATIONS AND THE EVERYDAY OF WOMEN EJA STUDENTS}

\section{ABSTRACT}

This article is the result of research of a qualitative nature carried out from testimonies collected through semi-structured interviews. An issue is discussed here concerning the negotiations that working women and mothers of young children establish in their homes in order to guarantee the possibility of attending night school. In this sense, the research is part of the work that discusses how gender relations are established in everyday life.

KEYWORDS: Adult education. Gender. Conciliation studying-work.

\section{RECONFIGURACIÓN DE LAS RELACIONES DE GÉNERO Y COTIDIANIDAD}

\section{DE LAS MUJERES ALUMNAS DE LA EJA}

\section{RESUMEN}

Este artículo es resultado de una investigación cualitativa hecha de testimonios recogidos a través de entrevistas semiestructuradas. Se discute aquí un aspecto de las negociaciones que las trabajadoras y madres de niños pequeños establecen en sus hogares

con el fin de garantizar la posibilidad de asistir a la escuela nocturna. En este sentido, la investigación forma parte del ámbito de trabajo para discutir cómo se establecen las relaciones de género en la vida cotidiana.

PALABRAS CLAVE: Educación de adultos. Género. Conciliación escuela-trabajo. 


\section{INTRODUÇÃO}

Nesta pesquisa, de natureza qualitativa, debruçamo-nos sobre o processo de escolarização de mulheres, trabalhadoras, mães ou responsáveis por crianças em idade escolar, realizando entrevistas no biênio 2013-2014 com apoio da Fundação de Amparo à Pesquisa do Estado de Minas Gerais (Fapemig). Buscamos verificar se havia e quais seriam os efeitos sobre a vida familiar de tais mulheres após o retorno à escola na modalidade Educação de Jovens e Adultos (EJA).

Pautamo-nos na coleta de depoimentos por meio de entrevistas semiestruturadas com alunas da 2a etapa do ensino fundamental do turno da noite. Tais entrevistas nos permitiram conhecer as negociações que mulheres trabalhadoras e mães estabelecem em suas residências com vistas a garantir a possibilidade de frequentarem a escola. Os resultados trazem à luz aspectos referentes às relações de gênero e ao trabalho doméstico, eminentemente quanto à divisão das tarefas domésticas, especialmente aquelas relativas ao cuidado da casa e dos filhos.

A hipótese com que trabalhamos neste artigo é a de que a permanência das mulheres na escola se garante com base numa reconfiguração das relações de gênero em suas residências a partir de suas performances como trabalhadoras e estudantes. Essa hipótese emerge dos dados coletados, reafirmando uma evidência que já se fez notar em outros trabalhos, como em Bastos (2011). Em sua pesquisa, a autora traz o depoimento de Generosa, 45 anos de idade, egressa do ensino médio na EJA, quem, até o momento da pesquisa, era aluna de graduação no curso de História: "As coisas de casa ficam por minha conta, para depois que chego do serviço e da faculdade. Mas quem cuida das coisas da minha menina é o meu marido. Ele cuida da comida, do uniforme, do para casa. E isso já me alivia muito. Eu posso estudar sem ficar preocupada com ela" (BASTOS, 2011, p. 71). No depoimento, vemos que, embora ainda atribua a si mesma as responsabilidades de casa, Generosa recorre ao verbo "cuidar" ao se reportar à ação do marido.

Tratamos de entrevistar um grupo de mulheres, negras (pretas ou pardas) em sua maioria, com pouco acesso anterior à escolarização e ocupação laboral em atividades de cuidado, como empregadas domésticas, babás e outras. Vemos que suas características de origem familiar as aproximam de um público de perfil já conhecido dos estudos da EJA: de famílias numerosas, filhas de mães e pais que não tiveram acesso à escola e atuavam como trabalhadores do campo.

Educação \& Formação, Fortaleza, v. 2, n. 6, p. 42-53, set./dez. 2017

DOI: http://dx.doi.org/10.25053/edufor.v2i6.2138

http://seer.uece.br/redufor 
Nesse contexto, as mulheres são precocemente levadas ao trabalho doméstico na sua residência ou em outras (de madrinhas, tias, conhecidos), como forma de garantir a própria manutenção ou contribuir com a manutenção da família. Fonseca (2004) chama a atenção para o fato de que a circulação de crianças e o trabalho de mulheres pobres são eventos que se verificam na história de mulheres no Brasil.

Contudo, nossos resultados apontaram para uma flexibilização das divisões de tarefas. As negociações que estabelecem em seu cotidiano forçam a revisão e a ampliação dos limites das responsabilidades domésticas, embora se possa também verificar a existência de um sobre-esforço em alguns casos. Na maior parte dos casos, verificamos a adaptação familiar. Sua inserção em atividades escolares leva outros membros da família (maridos, filhos ou outros parentes) a corresponsabilizarem-se pelo trabalho doméstico e pelo cuidado das crianças.

\section{ORGANIZAÇÃO FAMILIAR E TRABALHO DE CUIDADO}

Entendemos por cuidado aquelas atividades relativas à alimentação, limpeza e organização da casa, ou seja, à manutenção do lar. Incluem ainda orientação dos filhos nos aspectos morais (aprendizado de regras de convivência) e atinentes ao seu desempenho escolar. Assim, incluem o acompanhamento da realização de atividades de aquisição e desenvolvimento de leitura e escrita, a frequência às reuniões de pais, a supervisão do seu material e uniforme escolar e o seu transporte à escola.

Ampliando a compreensão da noção, na citação abaixo vemos que o trabalho doméstico, remunerado e não remunerado, é considerado trabalho de cuidado:

\footnotetext{
Se quiséssemos definir de maneira muito rigorosa o que é o care, seria: é o tipo de relação social que se dá tendo como objeto outra pessoa. Descascar batatas é care, mas de uma forma muito indireta: é care porque preserva a saúde, o outro ser. Fazer com que outro ser continue com saúde implica cozinhar, alimentá-lo, pois precisa desse cuidado material, físico. Então, pode-se dizer que tudo faz parte do care, mas aí não teríamos mais uma definição rigorosa de care. Deixar a casa limpa e agradável, deixar a cama cheirosa e agradável, passar o lençol, isso tudo pode fazer parte do trabalho de care da empregada doméstica ou da diarista, que deixa essas tarefas prontas. [...] Em números de 2009 (PNAD), seriam, no Brasil, 7 milhões e 223 mil pessoas em emprego doméstico, das quais 504 mil são homens e 6 milhões e 719 mil são mulheres. Será que podemos dizer que todas essas mulheres que fazem o trabalho doméstico remunerado são trabalhadoras de care? [...] Então, é importante estudar o que é o trabalho doméstico remunerado e o que é a relação social de cuidado, quando ele se profissionaliza. (HIRATA, 2010, p. 48).
}

Educação \& Formação, Fortaleza, v. 2, n. 6, p. 42-53, set./dez. 2017

DOI: http://dx.doi.org/10.25053/edufor.v2i6.2138

http://seer.uece.br/redufor 
Ao discutir o perfil das mulheres educandas da EJA, não podemos escapar às noções de gênero, raça/etnia, geração e classe social. Isso posto, lembramos que, ao nos aproximarmos de autores como Hall (2003), tomamos as noções acima não como essências universais que definem o ser (do sujeito) de modo permanente, fixo ou predeterminado. Antes, temos em mente que tais marcadores de diferença podem vir a ser ou não mobilizados discursivamente por esses sujeitos de forma ambivalente, em superposições. Procuramos explicitar melhor essa compreensão a seguir.

Interessa-nos a aproximação teórica com perspectivas de autoras feministas pós-coloniais, a partir das quais podemos pensar em como as mulheres elaboram suas identidades num processo relacional e histórico: "Inerentemente interdisciplinar, o feminismo examina os relacionamentos entre homens e mulheres e as consequências dos diferenciais de poder para a situação econômica, social e cultural das mulheres (e dos homens) em diferentes lugares e períodos da história" (BAHRI, 2013, p. 660).

Também a leitura de Bhabha (1998) nos remete a considerações acerca do terreno da cultura que podem acrescentar elementos à reflexão que desenvolvemos. $\mathrm{O}$ autor ressalta como os termos do embate cultural são produzidos performativamente numa constante sobreposição e deslocamento de domínios da diferença (de gênero, raça, classe, geração). Diz ele:

\footnotetext{
O presente não pode ser mais encarado simplesmente como uma ruptura ou um vínculo com o passado e o futuro, não mais uma presença sincrônica: nossa autopresença mais imediata, nossa imagem pública, vem a ser revelada por suas descontinuidades, suas desigualdades, suas minorias. (BHABHA, 1998, p. 23).
}

Ao tratar dos depoimentos das entrevistadas, vemos como nos seus discursos as atribuições de responsabilidades são marcadas por compreensão de gênero decorrentes de contingências mobilizadas pela classe e geração. Sua inserção no mundo do trabalho se fez precocemente, na infância. As aprendizagens necessárias à função são assimiladas no âmbito familiar, transmitidas como herança de uma geração a outra. E o trabalho doméstico apresentou-se como a opção possível para quem não teve acesso à formação profissional especializada.

Para conhecermos um pouco mais sobre o perfil das entrevistadas ${ }^{1}$, apresentamos a tabela adiante, a qual dispõe sobre o número de filhos ou netos dependentes.

1 Utilizamos nomes fictícios para preservação da identidade dos sujeitos.

Educação \& Formação, Fortaleza, v. 2, n. 6, p. 42-53, set./dez. 2017

DOI: http://dx.doi.org/10.25053/edufor.v2i6.2138

http://seer.uece.br/redufor 
Tabela 1 - Perfil das entrevistadas

\begin{tabular}{c|c|c|c|}
\hline Nome & Idade & Número de filhos ou netos & Idade dos filhos ou netos \\
\hline Terezinha & 61 & 1 & 12 \\
Hilda & 59 & 1 & 13 \\
Gilda & 55 & 1 & 7 \\
Sílvia & 50 & 2 & 1 e 6 \\
Alice & 46 & 1 & 12 \\
Elizabeth & 40 & 2 & 8 e 11 \\
Lúcia & 41 & 1 & 13 \\
Joana & 38 & 5 & Entre 9 e 22 \\
Léia & 38 & 2 & 4 e 13 \\
Rosângela & 33 & 2 & 11 e 14 \\
\hline
\end{tabular}

Fonte: Elaboração própria (2014).

Encontramos as entrevistadas em vivências que podemos descrever como ambivalentes: descontínuas, divididas, presas a identidades e interesses conflitantes, como se vê no depoimento a seguir, que aborda a questão de suas possibilidades de convivência com os filhos:

Meu marido é que faz, porque eu acordo de manhã e só chego, assim, à noite, depois que eu comecei a estudar. Mas eu, só final de semana, ou dia de domingo, eu, mais ou menos, ajeito a casa. Dia de sábado, eu não trabalho. Então, ele dá uma arrumada, eu fico com meus filhos e tudo. Agora dia de semana, ai já ficam [os filhos] na escola o dia inteiro... é isso. (Léia, estudante da EJA, 38 anos).

As manifestações desses sujeitos sociais apontam, portanto, como dissemos antes, para como se configuram suas identidades de educandas, mães, trabalhadoras, num processo de sobreposição, concomitância, e não necessariamente de linearidade. A constituição identitária como estudante inclui idas e vindas. As interrupções no processo escolar foram ocasionadas tanto por sua inserção precoce no mercado de trabalho como pelo casamento e constituição de família.

Com relação aos afastamentos da escola, vemos: 60\% devido ao trabalho e $40 \%$ distribuídos igualmente entre casamento, gravidez, mudança de residência da família e desinteresse pelo estudo.

Entretanto, destacaram-se nos depoimentos as negociações, inseridas em relações de poder no âmbito doméstico. As disputas nas relações de gênero desencadeadas no seu cotidiano emergem como relevantes indícios de não fixidez do seu lugar social, como vemos no depoimento a seguir, em que a depoente relatou a divisão das tarefas em sua residência:

\footnotetext{
Uai, eu sempre peço para um colher o lixo, botar o lixo para fora; para um lavar vasilha; para um varrer o terreiro; para um lavar o banheiro; para um colocar roupa na máquina; para um pegar roupa da máquina e estender ou pegar roupa do varal e dobrar... entendeu? A gente divide, cada sábado um pega o banheiro para dar aquela geral. (Léia, estudante da EJA, 38 anos).
}

Educação \& Formação, Fortaleza, v. 2, n. 6, p. 42-53, set./dez. 2017

DOI: http://dx.doi.org/10.25053/edufor.v2i6.2138

http://seer.uece.br/redufor 
A seguir trazemos outro depoimento acerca da manutenção da casa, em que a entrevistada destacou algumas exigências estabelecidas por ela:

\begin{abstract}
Colaborar que eu falo é o seguinte: se eu chegar aqui e pegar a cozinha arrumada, eu faço janta; se eu chegar e pegar a cozinha bagunçada, eu não vou fazer o jantar, porque eu não vou arrumar cozinha primeiro para depois eu fazer o jantar; com o Felipe [filho] dentro de casa na parte da manhã - porque o Felipe estuda à tarde -, então dá para ele arrumar de manhã, e o Luiz a mesma coisa, dá para ele arrumar de manhã, porque ele sai de casa às 11h30. Então, nesse período dá para ele arrumar a cozinha, varrer a cozinha, lavar as vasilhas que eles mesmos estão sujando. (Joana, estudante da EJA, 38 anos).
\end{abstract}

Neste outro depoimento, vemos a descrição de um conflito em torno do acompanhamento das atividades escolares do filho:

O Artur, quem ajuda ele mais é o pai, sabe? o pai sempre ajuda, porque o pai tem o tempo maior, né. O pai chega bem primeiro do que eu, e o Artur prefere sempre o pai, porque o pai dá muita colher de chá, e eu já sou bem mais rígida. Então, há uma discussão muito grande entre mim e o meu marido, porque eu falo: 'Não! Tem que ensinar o Artur dessa forma!'; Ele: 'Não! Não precisa ser dessa forma, não! Pode ser dessa!', sabe? Aí a gente fica entrando sempre em conflitos; aí tem vez que eu deixo assim: fica uns dias, até um mês, sem tomar conceito assim bem mesmo, de tomar a frente; mas aí, depois que eu tomei essas atitudes, eu vi que o Artur caiu muito na escola, aí retomei a discussão com o marido: 'Está vendo por que o Artur está assim? Eu vou ensinar do jeito certo e correto; você acha que não, que eu sou ignorante, que não sirvo para ensinar; você quer ser muito bom! Acha que está ajudando o Artur, mas está é prejudicando!', entendeu? (Joana, estudante da EJA, 38 anos).

Na sequência do mesmo depoimento, vemos como se dá o controle exercido pela mãe sobre as mesmas atividades escolares do filho:

\begin{abstract}
Agora eu comecei, quero ver o caderno do Artur todos os dias quando eu chegar; no final de semana, eu sempre falo com ele: 'O Artur não vai sair enquanto eu não ver os cadernos dele', porque, se tiver alguma coisa incompleta, sem fazer, eu coloco ele para fazer; se o pai dele está lá, ele começa a chorar, faz um escândalo, sabe? Aí agora o pai dele está caindo um pouco na real, entendeu? Do jeito que ele estava indo com o Artur não estava certo, entendeu? Inclusive, antes de ontem, o Artur deixou de fazer o para casa, sabe? Aí eu cheguei lá em casa e falei com o Ferreira: 'Você está vendo como que o Artur está? Ele não fez o para casa', aí tinha um bilhete para assinar que a professora tinha mandado; aí ele pegou e falou assim: 'Agora você vai falar com sua mãe', aí eu falei: 'Que é que está acontecendo? Fala logo!'. (Joana, estudante da EJA, 38 anos).
\end{abstract}

Nos termos de Bhabha (1998), mais uma vez é o espaço da intervenção que emerge nos interstícios culturais. Destacamos que esse alargamento das fronteiras das responsabilidades atribuídas à mãe no ambiente doméstico não pode ser generalizado, tampouco podemos incorrer no risco de uma leitura superficial ou apressada.

Educação \& Formação, Fortaleza, v. 2, n. 6, p. 42-53, set./dez. 2017

DOI: http://dx.doi.org/10.25053/edufor.v2i6.2138

http://seer.uece.br/redufor 
Como vimos no trabalho de Ávila (2010), as mães que conseguem uma efetiva renegociação são as que permaneceram na sua busca de escolarizar-se. As demais acabam abrindo mão da frequência à escola, como vemos no trecho abaixo:

\begin{abstract}
Dentre todos, somente o marido de Luzia parece ter assumido uma atitude de não cooperação, negando-se a cuidar do filho à noite para que ela pudesse estudar. A não cooperação por parte do marido de Luzia foi uma postura isolada, uma exceção [em relação aos demais sujeitos da pesquisa]. Mas essa atitude acabou por levá-la a desistir de estudar na UFSJ [Universidade Federal de São João del-Rei]. Daí a necessidade de chamar a atenção para a importância da postura de cooperação dos demais maridos. A despeito das limitações de alguns quanto a ajudar em determinados tipos de trabalhos domésticos, a despeito da inconstância e da seletividade da ajuda prestada, a ajuda dos maridos no cuidado com os filhos tem-se apresentado como um fator determinante para o sucesso escolar das universitárias que têm filhos pequenos. (ÁVILA, 2010, p. 107).
\end{abstract}

Nesse depoimento, o verbo "ajudar" ainda é usado pela depoente. Destaca-se que não há a compreensão de que a divisão não seja uma responsabilidade exclusiva da mãe. Passemos a seguir a uma maior aproximação da discussão da relação entre trabalho remunerado e escola na vida dessas educandas.

\title{
3 TRABALHO REMUNERADO E ESCOLA
}

Dizer que são mulheres negras exige que nos atenhamos a alguns aportes teóricos. No texto intitulado "Negros e a educação no Brasil", Gonçalves (2003) refere-se à defasagem entre brancos e não brancos ao se comparar as oportunidades e chances educacionais como arqueconhecidas. Para ratificar essa afirmação, o referido autor cita a obra Discriminação $e$ desigualdades raciais no Brasil, de autoria de Hasenbalg, datada de 1979. Por sua vez, o pesquisador Hasenbalg, em entrevista a Guimarães (2006), aponta que a pesquisa sobre desigualdades raciais no Brasil não é nova nem escassa, assim lembra que há mais de 25 anos de tradição de estudos sobre as desigualdades raciais no Brasil. Isso sem precisar remontar à conhecida pesquisa da Organização das Nações Unidas para a Educação, a Ciência e a Cultura (Unesco) no pós-Guerra, que procura identificar a origem da democracia racial brasileira e acaba por descobrir, ao contrário, a existência de um racismo à brasileira.

Tais estudos dão "[...] sustentação à idéia [sic] de que brasileiros não brancos estão expostos a desvantagens cumulativas ao longo das fases do ciclo de vida individual e que essas

Educação \& Formação, Fortaleza, v. 2, n. 6, p. 42-53, set./dez. 2017

DOI: http://dx.doi.org/10.25053/edufor.v2i6.2138

http://seer.uece.br/redufor 
desvantagens são transmitidas de uma geração a outra" (GUIMARÃES, 2006, p. 261). Na sequência, afirma que a temática dos não brancos e o mercado de trabalho é que está mais estudada. Lembra que ao nascer as diferenças já se manifestam; as mulheres negras concentram a maioria de casos de morte intrauterina, maior taxa de mortalidade infantil e maior taxa de mortalidade de menores de cinco anos. $\mathrm{O}$ acesso à escola e sua trajetória escolar se manifestam na estrutura ocupacional e nos rendimentos, que afetam, por sua vez, questões referentes ao acesso à moradia, à segurança e à educação dos filhos.

Além disso, representações negativas tendem ainda a regular as aspirações, tendendo o sujeito a manter-se no âmbito do socialmente (culturalmente) imposto. Hasenbalg salienta que pretos e pardos estão expostos a desvantagens em todas as etapas da vida. Afirma que a questão educacional parece estar se constituindo como o nó górdio das desigualdades raciais no nosso país (GUIMARÃES, 2006).

Dessa forma, ao focar essas mulheres, estamos diante de um fenômeno que confirma as estatísticas - estão em piores posições educacionais, de renda e ocupacionais. Assim, a maior parte desse grupo dedica-se a atividades relativas ao trabalho doméstico ou ao cuidado (care).

Tabela 2 - Ocupação das entrevistadas

\begin{tabular}{c|c}
\hline Ocupação & Quantidade \\
\hline Aposentada (Cozinheira) & 1 \\
\hline Babá & 1 \\
\hline Cabeleireira & 1 \\
\hline Copeira & 1 \\
\hline Cozinheira & 1 \\
\hline Empregada doméstica & 2 \\
\hline Manicure & 2 \\
\hline Trabalho não remunerado & 1 \\
\hline Serviços gerais & 1 \\
\hline
\end{tabular}

Fonte: Elaboração própria (2014).

É importante considerar alguns aspectos acerca da sua condição de trabalhadoras autônomas, apontados por Sorj, Fontes e Machado (2007, p. 575):

O significativo crescimento do trabalho informal na última década indica que um contingente cada vez maior de trabalhadores encontra-se desprotegido de direitos trabalhistas básicos, notadamente as cônjuges e chefes de família monoparentais, que estão proporcionalmente mais representadas no segmento informal da economia.

Educação \& Formação, Fortaleza, v. 2, n. 6, p. 42-53, set./dez. 2017 
Para aqueles que estão no mercado de trabalho formal, os benefícios sociais garantidos são, ainda assim, reduzidos. Não há férias remuneradas ou a possibilidade de licenças de saúde. Quanto a isso, concordamos com Quirino e Fidalgo (2009), quando asseveram que distinguir trabalho doméstico não remunerado de trabalho doméstico remunerado é crucial para o entendimento das características do trabalho da mulher. $\mathrm{O}$ trabalho feminino engloba tanto a participação na produção social, em trabalhos assalariados, como o trabalho reprodutivo, exercido no espaço privado da família.

O trabalho doméstico não remunerado é definido por Fougeyrollas-Schwebel (2009) como um conjunto de tarefas relacionadas ao cuidado das pessoas e que são executadas no contexto da família - domicílio conjugal e parentela -, realizado essencialmente por mulheres gratuitamente. Quando uma mulher contrata uma terceira para executar essas tarefas, isto é, prestar tais serviços para uma família diferente da sua, esse trabalho doméstico converte-se em serviço doméstico remunerado.

Kergoat (2001, p. 89), há mais de uma década, a partir da realidade francesa, observava que mudanças se deram ao longo dos anos na sociedade, mas, no fundo, o panorama permanecia inalterado:

\footnotetext{
A divisão sexual do trabalho tem por características a designação prioritária dos homens à esfera produtiva e das mulheres à esfera reprodutiva, como também, simultaneamente, a captação pelos homens nas funções com forte valor social agregado (políticos, religiosos, militares, etc.). Esta forma de divisão social tem dois princípios organizadores: o princípio da separação (há trabalhos de homem e trabalhos de mulher) e o princípio hierárquico (um trabalho de homem 'vale' mais que um trabalho de mulher).
}

Além da educação, o trabalho, segundo a autora, é a via fundamental para a superação da condição em que vivem essas trabalhadoras. Também nesse sentido, Ávila (2009) destaca que, por suas jornadas se constituírem a partir do trabalho doméstico remunerado e do trabalho doméstico não remunerado, não há, em princípio, tempo dedicado à escolarização.

Quando o sujeito que estuda é uma trabalhadora doméstica com filhos e companheiro, manter-se na escola exige articulação familiar, tendo em vista o horário das aulas, que, em geral, ocorrem à noite, como no caso das entrevistadas desta pesquisa.

Com base em nossos dados e concordando com autora acima (ÁVILA, 2009), é possível concluir que, para as empregadas domésticas e demais trabalhadoras que se mantêm estudando, 
frequentar a escola é uma forma de resistência individual. Assim, a autora citada frisa que o acesso à escola, sempre interrompido e retomado, vira uma forma de resistência no cotidiano à dominação/exploração que aprisiona a trajetória de vida dessas mulheres; a escola importa, para além do fato de quererem ou não se manter no trabalho doméstico remunerado. Trata-se, em primeiro lugar, de não deixar que o trabalho doméstico remunerado se torne um imperativo em suas vidas, pois estudar é percebido como uma forma de construir a possibilidade de fazer escolhas.

Nessa mesma perspectiva, Ávila (2013, p. 231) aponta que o estudo é o caminho para provar que é possível alcançar outras profissões e gerar mudanças em suas vidas:

[...] En mi investigación me interesó trabajar también con las resistencias, y una forma de resistencia es que las trabajadoras continúan estudiando, aun realizando trabajo remunerado. $Y$ esto constituye una de las estrategias de resistencia, porque el hecho de estudiar no es valorado ni por las patronas ni por la sociedad: ¿qué podría hacer con el estudio, si ella es una empleada doméstica? Como si hubiera una naturalización de esa condición. En cambio, para las trabajadoras, la escuela importa. Primero como nueva posibilidad, pero sobre todo para superar ese imperativo definitivo de que ellas no pueden acceder a otras profesiones. Se trata de una resistencia, en el sentido de su construcción profesional, y lo hacen con muchas dificultades.

\section{CONSIDERAÇÕES FINAIS}

Sem dúvida, as estruturas familiares passaram a apresentar mudanças nas últimas décadas. A redução do número de filhos por mulheres e a inserção cada vez maior delas no mercado de trabalho são dados que podem ser facilmente verificados. Mas, para as mulheres, as demandas laborais conflitam com os cuidados da família, principalmente no caso das mulheres mães com filhos pequenos. Acrescente-se aí maiores dificuldades de conciliação entre as diferentes demandas quando são somadas exigências escolares às necessidades laborais e familiares. Segundo Sorj, Fontes e Machado (2007), as formas de inserção das mulheres no mercado de trabalho variam conforme os tipos de famílias em que elas estão incluídas, de mesmo modo o acesso a benefícios garantidos pela legislação trabalhista e à jornada integral de trabalho.

No caso da legislação brasileira, há benefícios que se garantem, sobretudo, no caso de trabalhadores com filhos pequenos, benefício do qual elas ficam excluídas, por não contarem com carteira assinada, tais como licença médica remunerada e outros. Há ainda o caso das mães com filhos com carteira assinada ou não em jornadas parciais que obtêm rendimentos mais baixos.

Educação \& Formação, Fortaleza, v. 2, n. 6, p. 42-53, set./dez. 2017

DOI: http://dx.doi.org/10.25053/edufor.v2i6.2138

http://seer.uece.br/redufor 
Esse quadro leva a considerar que aquelas mulheres que não contam com o apoio de parceiros, filhos maiores ou parentes no cuidado familiar ficam impedidas de frequentar a escola. A ausência de creches no período noturno ou de atendimento às crianças na própria escola em que a mãe estuda torna-se um dado a ser considerado no âmbito de proposição de políticas públicas para as mulheres. A solução pode não vir a ser considerada adequada se pensarmos no atendimento à infância, já que a criança muitas vezes já frequenta a escola o dia todo. Entretanto, o que se vê por vezes é que algumas mulheres se fazem acompanhar à noite por seus filhos na escola.

Concluímos, portanto, por um lado, que as reconfigurações de relações de gênero assumiram preponderância significativa para aquelas mulheres que conseguiram se manter na escola à noite. Por outro lado, as mulheres mães ou responsáveis por crianças pequenas que não contaram com apoio de algum adulto (parente ou companheiro) permaneceram, mais uma vez, impedidas de frequentar a escola.

\section{REFERÊNCIAS}

ALVES, F. E. Mulheres trabalhadoras, sim. Alunas, por que não? Estudos sobre gênero, trabalho e educação na Bahia. 2006. 141 f. Dissertação (Mestrado em Educação) - Programa de Pós-Graduação em Educação, Universidade Católica de Brasília, Brasília, DF, 2006.

ÁVILA, M. B. Mesa de discusión sobre trabajo doméstico. Revista de Estudios Sociales, Bogotá, n. 45, p. 229-232, 2013.

ÁVILA, M. B. Vida cotidiana: um desafio teórico político para o feminismo. Cadernos de Crítica Feminista, Recife, v. 3, n. 2, p. 44-79, 2009.

ÁVILA, R. C. Trajetórias e estratégias escolares de mulheres que vivenciam uma tríplice jornada diária: trabalho remunerado, trabalho doméstico e estudos. 2010. 233 f. Dissertação (Mestrado em Educação) - Programa de Pós-Graduação em Processos Socioeducativos e Práticas Escolares, Universidade Federal de São João Del-Rei, São João Del-Rei, 2010.

BAHRI, D. Feminismo e/no pós-colonialismo. Estudos Feministas, Florianópolis, v. 21, n. 2, p. 659688, 2013.

BASTOS, L. C. Traçando metas, vencendo desafios: experiências escolares de mulheres egressas da EJA. 2011. 134 f. Dissertação (Mestrado em Educação) - Programa de Pós-Graduação em Educação, Universidade Federal de Minas Gerais, Belo Horizonte, 2011.

BHABHA, H. O local da cultura. Belo Horizonte: UFMG, 1998.

Educação \& Formação, Fortaleza, v. 2, n. 6, p. 42-53, set./dez. 2017

DOI: http://dx.doi.org/10.25053/edufor.v2i6.2138

http://seer.uece.br/redufor 
FONSECA, N. En búsqueda de más aliados y aliadas. Revista Observatório Social, n. 5, 2004.

FOUGEYROLLAS-SCHWEBEL, D. Trabalho doméstico. In: HIRATA, H. et al. (Org.). Dicionário crítico do feminismo. São Paulo: Unesp, 2009. p. 256-261.

GONÇALVES, L. A. Negros e educacão no Brasil. In: LOPES, E. M. T.; FARIA FILHO, L. M.; VEIGA, C. G. (Org.). 500 anos de educação no Brasil. Belo Horizonte: Autêntica, 2003. p. 325-346.

GUIMARÃES, A. S. Entrevista com Carlos Hasenbalg. Tempo Social, São Paulo, v. 18, n. 2, p. 259268, 2006.

HALL, S. Da diáspora: identidade e mediações culturais. Belo Horizonte: UFMG, 2003.

HIRATA, H. Teorias e práticas do care: estado sucinto da arte, dados de pesquisa e pontos em debate. In: FARIA, N.; MORENO, R. (Org.). Cuidado, trabalho e autonomia das mulheres. São Paulo: SOF, 2010. p. 42-56.

KERGOAT, D. Le rapport de sexe: de la reproduction des rapports sociaux à leur subversion. Actuel Marx, Paris, n. 30, p. 85-100, 2001.

MARUANI, M. Emprego. In: HIRATA, H. et al. (Org.). Dicionário crítico do feminismo. São Paulo: Unesp, 2009. p. 85-89.

MELO, H. P. O serviço doméstico remunerado no Brasil: de criadas a trabalhadoras. Rio de Janeiro: Ipea, 1998.

MELO, H. P.; CONSIDERA, C.; SABBATO, A. Os afazeres domésticos contam! Economia e Sociedade, Campinas, v. 31, p. 168-185, 2007.

QUIRINO, R.; FIDALGO, F. A conquista da cidadania da mulher pelo acesso ao trabalho produtivo. In: CONGRESSO DA ARIC, 12., 2009, Florianópolis. Anais... Florianópolis: UFSC, 2009.

REIS, S. M. O. A. A inserção dos egressos da educação popular na escola pública: tensão entre regulação e emancipação. 2009. 199 f. Dissertação (Mestrado em Educação) - Programa de Pós-Graduação em Educação, Universidade Federal de Minas Gerais, Belo Horizonte, 2009.

SILVA, J. A. Um estudo sobre as especificidades dos/as educandos/as da Educação de Jovens e Adultos - EJA: tudo junto e misturado! 2011. 191 f. Dissertação (Mestrado em Educação) - Programa de Pós-Graduação em Educação, Universidade Federal de Minas Gerais, Belo Horizonte, 2011.

SORJ, B.; FONTES, A.; MACHADO, D. C. Políticas e práticas de conciliação entre família e trabalho no Brasil. Cadernos de Pesquisa, São Paulo, v. 37, n. 132, p. 573-594, 2007.

Recebido em 8 de outubro de 2016.

Aceito em 18 de março de 2017.

Educação \& Formação, Fortaleza, v. 2, n. 6, p. 42-53, set./dez. 2017

DOI: http://dx.doi.org/10.25053/edufor.v2i6.2138

http://seer.uece.br/redufor 